\title{
PERHITUNGAN LAJU INFILTRASI PADA KEBUN PERCONTOHAN FAKULTAS TEKNOLOGI PERTANIAN UNIVERSITAS PAPUA
}

\section{(Calculation of Infiltration Rate in Pilot Garden of Faculty Agricultural Technology, Papua University)}

\author{
Bertha Ollin Paga, ${ }^{1 *)}$ dan Reniana ${ }^{1)}$ \\ ${ }^{1 *)}$ Program Studi Teknik Pertanian dan Biosistem, Fakultas Teknologi Pertanian Universitas Papua \\ Jl. Gunung Salju Amban-Manokwari-Papua Barat \\ Email: berthaollin@gmail.com
}

\begin{abstract}
The availability of water for agricultural crops is very fluctuating which is influenced by the season, the presence of springs, and water conservation efforts. Water supply for agriculture can be obtained through the provision of irrigation water, in which the provision of irrigation water must be known the infiltration rate so that no run-off occurs. Measurement of the infiltration rate can be done by various methods, including the Double Ring Infiltrometer method and the Horton method. The purpose of this study was to determine the infiltration rate that occurred in the Fateta Unipa demonstration plot. The method to be used is a descriptive analysis method with a quantitative approach. Measurement of the infiltration rate in the field was carried out at 1 (one) point with 3 (three) replications. Data processing is carried out by using 2 (two) processing techniques, namely the method of processing data directly from field measurements and data processing using the Horton Model. After that, a comparison is made between the direct measurement results and the measurement results using the Horton model. Based on the results of data processing, it was found that the infiltration rate at the study site, both with the infiltration and the Horton model, was 39.7 milli meter / minute and 21.7 milli meter / minute respectively. The infiltration rates of the two methods were not significantly different.
\end{abstract}

Keywords: Infiltration Rate, Ring Infiltrometer, Horton

\begin{abstract}
ABSTRAK
Ketersediaan air bagi tanaman pertanian sangat fluktuatif yang dipengaruhi oleh musim, keberadaan mata air, serta usaha-usaha pelestarian air. Persediaan air bagi pertanian dapat diusahakan melalui pengadaan air irigasi, yang mana dalam pemberian air irigasi tersebut harus diketahui laju infiltrasinya agar tidak terjadi run-off. Pengukuran laju infiltrasi dapat dilakukan dengan berbagai metode, diantaranya adalah dengan metode Double Ring Infiltrometer dan metode Horton. Tujuan penelitian ini adalah mengetahui laju infiltrasi yang terjadi di kebun percontohan Fateta Unipa. Metode yang akan digunakan adalah metode deskriptif analisis dengan pendekatan kuantitatif. Pengukuran laju infiltrasi di lapangan dilakukan pada 1 (satu) titik dengan 3 (tiga)kali ulangan. Pengolahan data dilakukan dengan 2 (dua) teknik pengolahan, yaitu dengan metode pengolahan data hasil pengukuran lapang secara langsung dan pengolahan data dengan menggunakan Model Horton. Setelah itu dilakukan perbadingan antara hasil pengukuran langsung dengan hasil pengukuran menggunakan model Horton. Berdasarkan hasil pengolahan data diperoleh bahwa laju infiltrasi pada lokasi penelitian, baik dengan infiltrasi maupun model horton adalah masing-masing sebesar 39,7 $\mathrm{mm} /$ menit dan $21,7 \mathrm{~mm} / \mathrm{menit}$. Laju infiltrasi dari dua metode tersebut tidak berbeda siqnifikan.
\end{abstract}

Kata Kunci: Laju Infiltrasi, Ring Infiltrometer, Horton 


\section{PENDAHULUAN}

Air merupakan kebutuhan utama tanaman terlebih khusus pada budidaya tanaman pertanian. Banyaknya air yang tersedia untuk pengairan pertanian sangat berbeda-beda atau bervariasi. Hal ini dipengaruhi oleh musim (dalam hal ini, musim hujan atau musim kemarau), lokasi untuk memperoleh air dan usaha-usaha perlindungan air lainnya. Penyediaan air untuk lahan pertanian dapat diusahakan dengan berbagai cara, misalnya dengan pembangunan irigasi. Namun dari setiap pengaplikasin air irigasi ini harus diketahui laju infiltrasinya agar tidak terjadi run-off atau aliran permukaan.

Infiltrasi dapat didefenisikan sebagai proses masuknya atau merembesnya air ke dalam permukaan tanah. Beberapa metode yang sering digunakan dalam pengukuran laju infiltasi ini, diantaranya adalah metode dengan menggunakan Double Ring Infiltrometer dan metode Horton. Metode Double Ring Infiltrometer dilakukan pengukuran secara langsung di lapangan. Sedangkan metode Horton dilakukan perhitungan menggunggukan persamaan, dimana varibel yang digunakan merupakan data hasil pengukuran dari metode Double Ring Infiltrometer. Model Horton ini merupakan salah satu model infiltrasi yang terkenal dalam hidrologi. Laju infiltrasi sangat sangat dipengaruhi oleh sifat fisik tanah dan kimia tanah. Sifat fisik tanah tersebut meliputi tekstur, permeabilitas tanah, bulk density, total ruang pori dan kadar air. Sementara sifat kimia tanah yang dimaksud adalah kandungan bahan organik.

Besar kecilnya laju Infiltrasi suatu lahan sangat bergantung pada keadaan hujan, sifat fisik dan keandungan air tanahnya, kondisi permukaan tanah serta pemanfaatan lahan tersebut.

Seperti yang telah diungkapkan sebelumnya bahwa lahan dengan berbagai variasi pemanfaatannya sangat mempengaruhi besar kecilnya laju infiltrasi yang terjadi pada lahan tersebut. Oleh sebab itu agar pengolahan lahan percontohan FATETA dapat berfungsi dengan baik maka perlu diketahui besar laju infiltrasinya.

Rumusan masalah pada penelitian ini antara lain sebagai berikut: a. Berapa besar laju infiltrasi pada kebun percontohan FATETA UNIPA?

b. Berapa besar perbedaan laju infiltrasi yang diperoleh dari hasil pengukuran dan perhitungan model infiltrasi Horton?

Penelitian ini sangat urgensi untuk dilakukan karena Wilayah Papua masih memiliki lahan yang sangat luas dan sangat berpotensi untuk pengolahan lahan pertanian. Namun, sampai saat ini masih banyak lahan kosong yang tidak diolah, masih jadi lahan tidur sementara untuk pemenuhan kebutuhan pangan masyarakat masih didatangkan dari luar papua, seperti dari Surabaya, Manado, Makassar dan sebagainya. Menurut informasi, salah satu penyebab masyarakat tidak bisa pengolah lahan pertanian tersebut adalah kurangnya ketersediaan air. Tanah Papua termasuk lahan kering sehingga untuk bercocok tanam masih bergantung pada hujan, belum memiliki bantuan teknologi irigasi. Dalam merancang pembangunan irigasi tersebut terlebih diketahui laju infiltrasi pada lokasi tersebut. Oleh sebab itu, pada kesempatan ini sebagai awal dari rencana tersebut, kita harus melakukan analisa laju infiltrasi pada suatu lokasi yang akan dijadikan sebagai sampel.

Penelitian ini akan membahas berapa besar laju infiltrasi yang terjadi dengan menggunakan metode pengukuran langsung dan perhitungan model Horton pada daerah percontohan FATETA UNIPA serta pengaruh sifat fisik tanah terhadap besar laju infiltrasi.

\section{Tujuan Penelitian}

Tujuan penelitian ini adalah mengetahui laju infiltrasi yang terjadi di kebun percontohan Fateta Unipa dan kegunaannya adalah akan diperolehnya data laju infiltrasi sehingga dapat digunakan sebagai data dalam pengolahan tanah sekaligus teknik pemberian air pada tanaman.

\section{METODOLOGI PENELITIAN}

\section{Alat}

Alat-alat yang digunakan pada penelitian ini adalah 2 buah ring infiltrometer masing-masing diameter $60 \mathrm{~cm}$ dan $30 \mathrm{~cm}$ dengan tinggi yang sama yaitu $50 \mathrm{~cm}$, penggaris, ember/gen untuk mengangkat air, skop, palu, balok kayu, stopwatch, kantong plastik, kertas label, ring 
sampel, cutter serta peralatan laboratorium lainnya untuk analisa sampel tanah.

\section{Bahan}

Adapun bahan yang digunakan adalah air dan sample tanah

\section{Prosedur Penelitian}

Pada penelitian ini digunakan metode deskriptif analisis dengan pendekatan kuantitatif. Metode ini merupakan metode penelitian yang dilakukan langsung dengan cara observasi, kemudian hasilnya diolah dan dianalisis untuk dapat kesimpulan.

Pengukuran laju infiltrasi di lapangan dilakukan pada 1 (tiga) titik dengan 3 kali ulangan. Pengolahan data dilakukan dengan 2 (dua) teknik pengolahan, yaitu dengan metode pengolahan data hasil pengukuran lapang secara langsung dan pengolahan data dengan menggunakan Model Horton. Setelah itu dilakukan perbadingan antara hasil pengukuran langsung dengan hasil pengukuran menggunakan model Horton.

Pelaksanaan penelitian ini dilakukan dengan 5 (lima) tahapan, yaitu sebagai berikut:

1. Tahap awal (persiapan lahan); lokasi sample dibersihkan dari rumput dan akarakar mati.

2. Pengambilan contoh tanah; meliputi tanah terganggu dan tanah utuh

3. Pengukuran besarnya laju infiltrasi dengan double ring infiltrometer; dilakukan pada 1 (satu) titik dengan 3x ulangan

4. Pengamatan dan pengujian sifat-sifat fisik tanah

5. Analisa data laju infiltrasi hasil pengukuran dan laju infiltrasi dengan model Horton

Analisa data laju infiltrasi dilakukan dengan menggunakan persamaan Horton sebagai berikut:

Dimana:

$$
f_{t}=f_{c}+\left(f_{0}-f_{c}\right) e^{-k t}
$$

$f_{t}=$ laju infiltrasi pada saat $\mathrm{t}(\mathrm{mm} / \mathrm{menit})$

$f_{c}=$ laju infiltrasi saat konstan $(\mathrm{mm} / \mathrm{menit})$

$f_{0}=$ laju infiltrasi saat awal $(\mathrm{mm} / \mathrm{menit})$

$k=$ konstanta geografis

$t=$ waktu

$e=2,718$

Dari rumus utama (persamaan 1) tersebut dapat ditentukan parameter-parameter yang akan digunakan dalam Metode Horton, diantaranya adalah:

a. $\quad k$ diperoleh dari persamaan linier:

$$
\begin{aligned}
& y=m x+c \\
& y=t x=\log \left(f-f_{c}\right) \\
& m=\frac{-1}{k \log e} \\
& c=\frac{-1}{k \log e} \log \left(f_{0}-f_{c}\right)
\end{aligned}
$$

Dengan menggunakan persamaan (4):

$$
m=\frac{-1}{k \log e}
$$

Maka:

$$
k=\frac{-1}{m \log e} \text { atau } k=\frac{-1}{0,4343 \times m}(6)
$$

Untuk mendapatkan nilai $m$ (gradien) dilakukan plotting antara infiltrasi aktual (f) $(\mathrm{cm} / \mathrm{jam})$ dengan $\log (\mathrm{f}-\mathrm{fc})(\mathrm{cm} / \mathrm{jam})$. Pada penelitian ini Plotting dikerjakan menggunakan Ms. Excel 2010.

b. $f_{c}$ merupakan besarnya infiltrasi pada saat telah mencapai keadaan steady/ konstan.

c. $f_{0}$ adalah nilai infiltrasi saat keadaan awal/intial condition.

$f_{0}$ dan $f_{c}$ tersebut dapat didapatkan dari hasil pengukuran. $f_{c}$ tergantung pada tipe tanah. Sementara $f_{0}$ dan $f_{c}$ adalah fungsi jenis tanah dan tutupan.

\section{HASIL DAN PEMBAHASAN}

\section{Kondisi Umum Lokasi Penelitian}

Lokasi penelitian berada tepat dalam Lokasi Kampus Induk Universitas Papua di kebun percontohan Fakultas Teknologi Pertanian. Lokasi tersebut berada dalam wilayah Kelurahan Amban Distrik Manokwari Timur Kabupaten Manokwari. Secara geografis, yang dilacak melalui aplikasi Google Earth Pro, lokasi penelitian berada antara $134^{0} 4^{\prime} 0^{\prime \prime}$ Bujur Timur dan 0050'20" Bujur Selatan.

Jenis tanah pada lokasi penelitian yang dilihat dari peta jenis tanah merupakan tanah Haprendolls. Gambar 1 menunjukkan peta jenis tanah pada lokasi penelitian. 


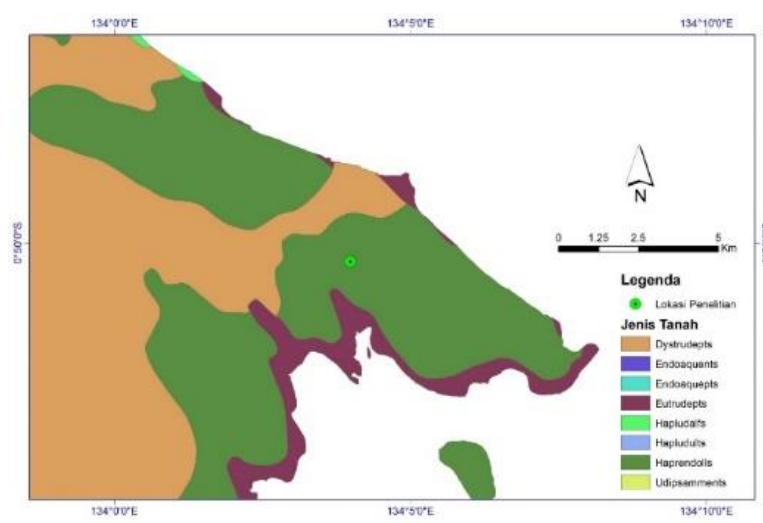

Gambar 1. Peta Jenis Tanah Lokasi Penelitian

Kandungan organik pada lokasi penelitian sebesar $75 \%$ berdasarkan peta Kandungan organik tanah. Kandungan bahan organik pada lokasi tersebut tegolong tinggi sehingga sangat memungkinkan untuk lahan pertumbuhan tanaman. Adapun peta kandungan organik tanah lokasi penelitian terlihat pada Gambar 2.

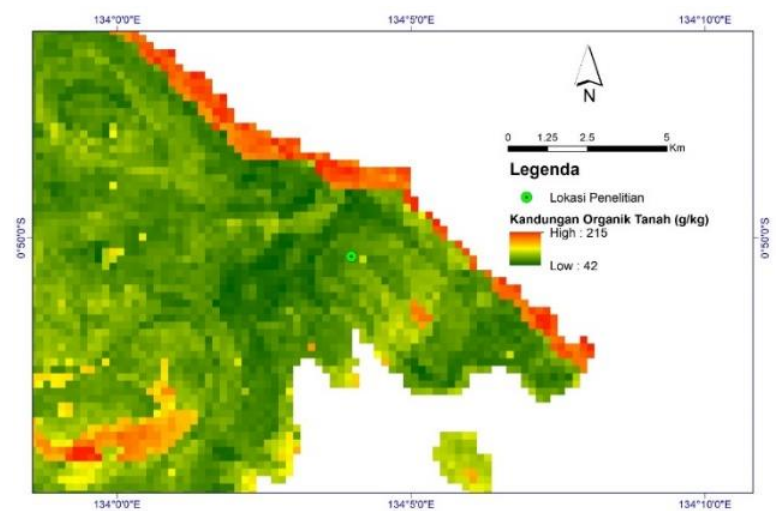

Gambar 2. Peta Kandungan Organik Tanah $(\mathrm{g} / \mathrm{km})$ Lokasi Penelitian

Sementara untuk sifat fisik tanah lokasi penelitian lainnya seperti kadar air rata-rata, kapadatan (bulk density), partikel density dan porositas berdasarkan analisa laboratorium dapat dilihat pada Tabel 1.

Tabel 1. Sifat Fisik Tanah Lokasi Penelitian

\begin{tabular}{clcc}
\hline No. & Sifat Fisik & Nilai & Satuan \\
\hline 1 & Kadar air rata-rata & 48,38 & $\%$ \\
2 & Bulk Density & 1,3 & $\mathrm{Gram} / \mathrm{cm}^{3}$ \\
3 & Partikel Density & 2,63 & $\mathrm{Gram} / \mathrm{cm}^{3}$ \\
4 & Porositas & 45,45 & $\%$ \\
\hline
\end{tabular}

Berdasarkan hasil analisa sample tanah pada lokasi penelitian, diperoleh kadar air ratarata sebesar 48,38 \%. Kadar air ini optimum untuk pertumbuhan tanaman, terutama untuk tanaman umbi-umbian karena berada di kedalaman perakaran efektif tanaman.
Besar kecilnya laju infiltrasi tanah juga dipengaruhi oleh banyaknya air (kadar air) yang terkadung pada tanah tersebut. Jika jumlah air dalam suatu tanah tinggi maka air yang akan masuk ke dalam tanah tersebut jumlahnya menjadi sedikit dan menyebabkan laju infiltrasi tanah menjadi kecil (David Muhammad, 2017). Sulistyono dan Romadhona (2017), juga menambahkan bahwa Kadar air kapasitas lapang marupakan kemampuan maksimum tanah dalam menyimpan air. Kadar air kapasitas lapang yang rendah akan menyebabkan air yang tersedia lebih rendah dan mengakibatkan tanaman akan lebih cepat layu bahkan mengalami kekeringan.

Untuk pengujian tekstur tanah pada penelitian ini, hanya dapat dilakukan dengan metode analisis ayakan sehingga hasil analisa diperolah bahwa tekstur tanah tergolong pasir halus sampai sedang. Adapun grafik hasil analisisnya dapat dilihat pada Gambar 3.

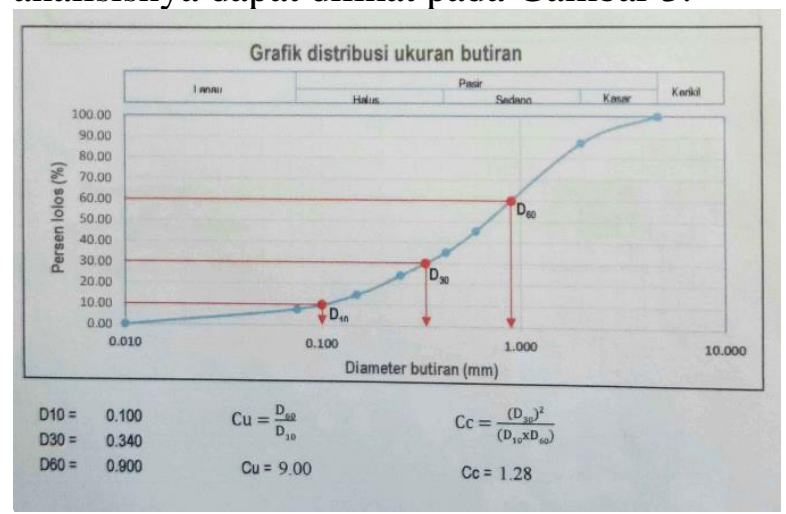

Gambar 3. Grafik Hasil Analisa Tekstur Tanah

\section{Laju Infiltrasi}

Berdasarkan hasil pengukuran yang di lapangan, memperlihatkan bahwa laju infiltarsi berbading terbalik dengan waktu. Semakin lama waktu untuk infiltrasinya maka akan semakin berkurang laju infiltrasi yang terjadi. Dengan berjalannya waktu air yang merembes ke dalam tanah akibat adanya pengaruh gaya tarikan gravitasi bumi lama kelamaan akan membuat lapisan tanah menjadi basah dan akan sampai pada titik jenuh air.

Waktu yang digunakan dalam pengamatan serta pengukuran infiltrasi pada penelitian ini adalah 1 jam (60 menit) dengan mencatat hasil penurunan air pada tiap waktu satu menit. Dari hasil pengukuran di Lapangan menggunakan Ring infiltrometer diperoleh data seperti yang tertuang pada tabel 1 . 
Tabel 1. Data Hasil Pengukuran Ring Infiltrometer

\begin{tabular}{ccccc}
\hline \multirow{2}{*}{$\begin{array}{c}\text { Waktu ke- } \\
\text { (menit) }\end{array}$} & \multicolumn{3}{c}{$\begin{array}{c}\text { Ring pada } \\
\text { perlakuan ke- }(\mathbf{m m})\end{array}$} & $\begin{array}{c}\text { Rata-rata } \\
(\mathbf{m m})\end{array}$ \\
\cline { 2 - 4 } & $\mathbf{1}$ & $\mathbf{2}$ & $\mathbf{3}$ & \\
\hline $\mathbf{1}$ & 5 & 8 & 6 & 6.3 \\
$\mathbf{2}$ & 5 & 6 & 5 & 5.3 \\
$\mathbf{3}$ & 5 & 5 & 5 & 5.0 \\
$\mathbf{5}$ & 4 & 5 & 4 & 4.3 \\
$\mathbf{8}$ & 4 & 4 & 4 & 4.0 \\
$\mathbf{1 2}$ & 3 & 3 & 4 & 3.3 \\
$\mathbf{1 6}$ & 3 & 3 & 3 & 3.0 \\
$\mathbf{2 4}$ & 2 & 3 & 3 & 2.7 \\
$\mathbf{3 6}$ & 2 & 2 & 3 & 2.3 \\
$\mathbf{4 9}$ & 2 & 2 & 2 & 2.0 \\
$\mathbf{5 6}$ & 1 & 1 & 1 & 1.0 \\
$\mathbf{6 0}$ & 0 & 1 & 0 & 0.3 \\
\hline
\end{tabular}

Grafik hubungan antara waktu dan penurunan air dalam ring infiltrometer (Laju infiltrasi)

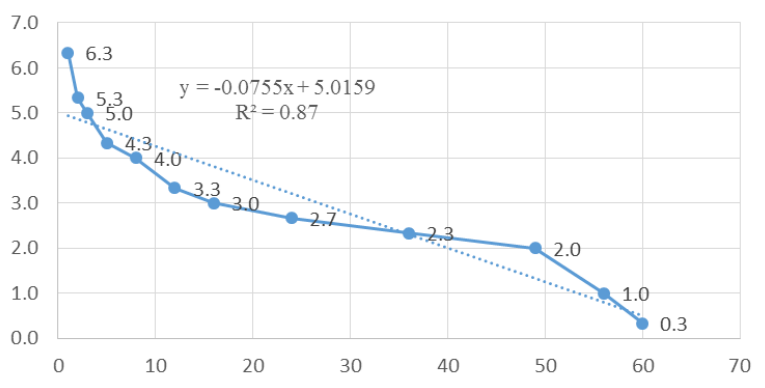

Grafik 1. Hubungan antara waktu dan laju infiltrasi dalam ring infiltrometer

Dari tabel data pengukuran (tabel 1) dan grafik 1 (Grafik hubungan antara waktu dan laju infiltrasi dalam ring infiltrometer dapat diketahui bahwa nilai $\mathrm{f}(\mathrm{o})=6,3 ; \mathrm{f}(\mathrm{c})=0,3$; 2.718; dan dari hasil ploting diperoleh nilai $\mathrm{m}$ (gradien) sebesar -0.0755. Sehingga, nilai k adalah 0.173843 . Dengan diketahuinya semua parameter tersebut maka pengolahan data dengan metode Horton dapat dilakukan. Dan diperoleh data analisis seperti pada Grafik 2.

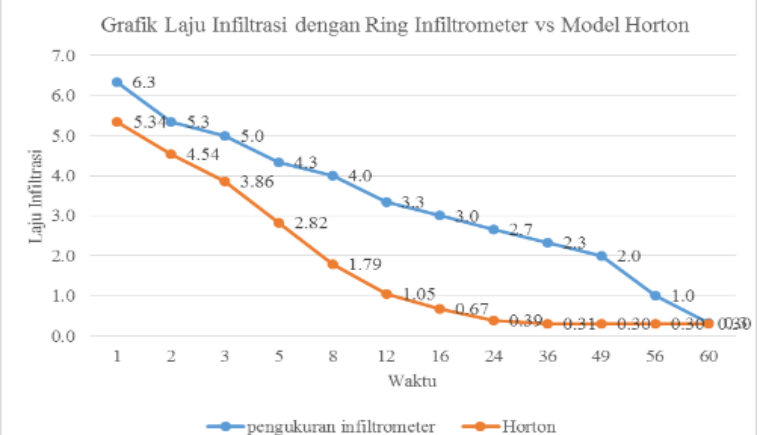

Grafil 2. Grafik laju infiltrasi ring infiltrometer dengan model horton
Dari grafik 2, terlihat bahwa baik laju infiltrasi dengan infiltrometer maupun model Horton mengalami penurunan seiring dengan bertambahnya waktu. Semakin lama waktu infiltrasinnya maka semakin berkurang laju infiltrasi (semakin sedikit jumlah air yang terinfiltrasi). Hal ini sesuai dengan pendapat Horton bahwa kapasitas infiltrasi akan berkurang seiring dengan pertambahan waktu dan akan mendekati kostant. Ia juga menambahkan bahwa faktor yang beroperasi di permukaan tanah dibanding dengan proses aliran yang terjadi lebih berpengaruh terhadap penurunan kapasitas infiltrasi dibanding dengan proses aliran yang terjadi di dalam tanah. Beberapa faktor yang berperan dalam mengurangi laju infiltrasi antara lain penutupan retakan tanah dan pembentukan kerak tanah, penghancuran struktur permukaan tanah serta pengangkutan partikel halus dipermukaan tanah yang disebabkan oleh percikan air hujan. Penutupan retakan tanah biasanya dari koloid tanah.

Jumlah keseluruhan air yang terinfiltrasi pada lokasi penelitian baik melalui pengukuran infiltrometer maupun dengan model Horton masing-masing adalah sebesar $39,7 \mathrm{~mm} /$ menit dan $21,7 \mathrm{~mm} /$ menit. Nilai ini tergolong rendah. Tinggi rendahnya infiltrasi sangat dipengaruhi oleh sifat fisik dan kimia tanah. Sifat fisik seperti kadar air, bulk density, partikel density, porositas, tekstur tanah. Sedangkan sifat kimia yaitu kandungan bahan organik.

Seperti yang telah diusaikan pada sub bab sebelumnya bahwa kadar air awal rata-rata pada lokasi penelitian adalah sebesar 48,38\%. Hal ini menandakan bahwa kemampuan tanah mengikat air pada lokasi penelitian tergolong tinggi. Dari penelitian yang dilakukan dapat dikatakan bahwa semakin tinggi kadar air tanah maka laju infiltrasi yang terjadi akan semakin lambat. Kadar air tanah sangat menentukan kelengasan pada suatu lokasi.

Dari hasil analisa tekstur tanah diperoleh tekstur tanah pada lokasi penelitian adalah berupa tekstur pasir halus sampai sedang. Dengan porositas sebesar 45,45\%. Jika diperhatikan dari tekstur tanah yang berpasir dan porositas yang lumayan besar maka infiltrasi yang akan terjadi juga seharusnya akan besar. Seperti yang diungkapkan oleh 
Ajidirman (2015) bahwa kemampuan tanah dengan bahan induk dari batu pasir dengan porositas yang besar akan dapat melewatkan air yang sangat besar juga. Namun, pada penelitian ini terjadi yang sebaliknya. Laju infiltrasi yang terjadi lambat. Hal ini disebabkan oleh kandungan bahan organiknya yang tergolong tinggi yaitu sekitar $75 \%$, juga memiliki bulk density sebesar $1,3 \mathrm{gram} / \mathrm{cm}^{3}$ serta pertikel density sebesar 2,63 gram $/ \mathrm{cm}^{3}$. Tanah yang dengan kandungan organik tinggi memiliki bulk density yang sangat rendah jika dibandingkan dengan tanah mineral. Bulk density merupakan tingkat kepadatan tanah. Tanah yang memiliki kepadatan tinggi akan memiliki bulk densitynya yang tinggi pula. Bulk density yang tinggi akan yang mengakibatkan semakin sulitnya meneruskan air atau ditembus oleh akar-akar tanaman. Menurut Mustafa, dkk, (2012) bahwa, kerapatan massa suatu tanah (bulk density) yang menunjukkan kepadatan tanah yaitu semakin padat tanah maka makin tinggi bulk density. Dan dengan padatnnya tanah tersebut berarti semakin sulit untuk meneruskan air dan atau ditembus oleh akar tanaman. Yunagardasari (2017), juga menambahkan bahwa kerapatan massa tanah yang cukup tinggi dapat mengakibatkan tanah menjadi lambat meloloskan air.

\section{KESIMPULAN}

Berdasarkan hasil analisa data dapat disimpulkan beberapa hal sebagai berikut:

1. Diperoleh laju infiltrasi pada lokasi penelitian, baik dengan infiltrasi maupun model horton adalah masing-masing sebesar 39,7 $\mathrm{mm} / \mathrm{menit}$ dan 21,7 $\mathrm{mm} / \mathrm{menit}$.

2. Laju infiltrasi dengan infiltrometer dengan model tidak berbeda siknifikan

3. Laju infiltrasi akan semakin berkurang seiring dengan pertambahan waktu.

\section{DAFTAR PUSTAKA}

Ajidirman (2015). Kajian Laju Infiltrasi Dalam Hubungannya Dengan Pergerakan Bahan Liat Penyusun Tubuh Tanah Berbahan Induk Batu Liat Dan Pasir. J. Solum Vol.2 No.2, Juli 2005: 74-80

David, Muhammad., (2017). Analisis Laju Infiltrasi Pada Tutupan Lahan

Perkebunan Dan Hutan Tanam Industri (HTI) Di Daerah Aliran Sungai (DAS) Siak. Jom FTEKNIK Volume 3 No. 2

Mustafa, dkk, (2012). Modul Pembelajaran Dasar-dasar Ilmu Tanah. Universitas Hasanuddin Makasar. 169 hal.

Sulistyono, Eko dan Romadhona Abdillah. (2017). Kadar Air Kapasitas Lapang dan Bobot Jenis Tanah yang Optimal untuk Pertumbuhan dan Produksi Umbi Uwi (Dioscorea alata L). Jurnal: AGROVIGOR 10 (1): 39 - 43

Yunagardasari, Cindy. (2017). Model infiltrasi pada berbagai penggunaan lahan di desa tulo kecamatan dolo kabupaten sigi. E-j. Agrotekbis 5 (3) : $315-323$. 